\title{
Combined transanal minimally invasive surgery (TAMIS) and retroperitoneal laparoscopy for resection of lymph node recurrence of ovarian cancer
}

\author{
B. lelpo ${ }^{1} \cdot$ V. Simó $^{1} \cdot$ E. Pastor ${ }^{1} \cdot$ J. Arredondo ${ }^{1} \cdot$ A. Villafañe ${ }^{1} \cdot$ S. Fuentes ${ }^{1} \cdot$ L. Padilla $^{2} \cdot$ V. Orille $^{2} \cdot$ E. Lorenzo $^{2}$. \\ A. Corona ${ }^{2} \cdot$ M. V. Diago'
}

Received: 28 May 2018 / Accepted: 1 September 2018 / Published online: 17 September 2018

(c) Springer Nature Switzerland AG 2018

To our knowledge no cases of transanal minimally invasive surgery (TAMIS) combined with retroperitoneal laparoscopy for resection of lymph node recurrence have been described in the literature.

We report a case of resection of mesorectal and paraaortic lymph node recurrence of primary ovarian cancer performed with retroperitoneal laparoscopy and TAMIS.

A 66-year-old female, diagnosed in December 2014 with stage IIa ovarian adenocarcinoma had cytoreductive surgery at that time, achieving a $\mathrm{R} 0$ resection (complete hysterectomy with bilateral ovariectomy, pelvic peritonectomy with standard lymphadenectomy and supramesocolic omentectomy). Surgery was followed by adjuvant treatment. On November 2017, a computed tomography scan revealed lymph node recurrence in the left para-aortic nodes $(2.5 \mathrm{~cm}$ diameter on CT) and mesorectal space (2.8 $\mathrm{cm}$ diameter) at $10 \mathrm{~cm}$ from the anal verge.

After a multidisciplinary session, both nodes were resected (see attached video). The para-aortic node was resected using retroperitoneal laparoscopy and the mesorectal node resected using a TAMIS approach [1-3]. The postoperative course was uneventful and the patient was discharged 5 days after surgery. Histopathological examination of the two nodes revealed undifferentiated serosal

Electronic supplementary material The online version of this article (https://doi.org/10.1007/s10151-018-1849-3) contains supplementary material, which is available to authorized users.

B. Ielpo

Ielpo.b@gmail.com

1 Department of General Surgery, León University Hospital, León, Spain

2 Department of Gynecology, León University Hospital, León, Spain adenocarcinoma of the ovary. No recurrence was found at 1-year follow-up.

Combination of different minimally invasive approaches is a safe alternative to conventional surgery for resection of lymph node recurrence that surgeons should be aware of.

\section{Compliance with ethical standards}

Conflict of interest The authors declare that they have no conflict of interest.

Ethical approval All procedures performed in this study were in accordance with the ethical standards of the institutional committee and with the 1964 Helsinki Declaration and its later amendments or comparable ethical standards.

Informed consent All participants provided informed consent prior to their participation.

\section{References}

1. Gilshtein H, Duek SD, Khoury W (2016) Transanal endoscopic microsurgery: current and future perspectives. SLEPT 26(3):e46-e49

2. Chung L, O'Dwyer PJ (2013) Laparoscopic resection of paraaortic or paracaval lesions: feasibility and outcome. Surg Endosc 27(11):4153-4156

3. Cortez AJ, Tudrej P, Kujawa KA et al (2018) Advances in ovarian cancer therapy. Cancer Chemother Pharmacol 81(1):17-38 